\title{
Effects of Alpha and Beta Adrenergic Blockade on Hepatic Glucose Balance Before and After Oral Glucose
}

\author{
Role of Insulin and Glucagon
}

\author{
Zvi Chap, Toshihiko Ishida, Jesse Chou, Lloyd Michael, Craig Hartley, Mark Entman, and James B. Field \\ Diabetes Research Center, St. Luke's Episcopal Hospital, Department of Medicine, Division of Endocrinology \& Metabolism, and Section \\ of Cardiovascular Science, Baylor College of Medicine, Houston, Texas 77030
}

\begin{abstract}
In conscious dogs, phentolamine infusion significantly increased fasting portal vein insulin, glucagon, and decreased net hepatic glucose output and plasma glucose. Propranolol significantly decreased portal vein insulin, portal flow, and increased hepatic glucose production and plasma glucose. Phentolamine, propranolol, and combined blockade reduced glucose absorption after oral glucose. $\alpha, \beta$, and combined blockade abolished the augmented fractional hepatic insulin extraction after oral glucose. Despite different absolute amounts of glucose absorbed and different amounts of insulin reaching the liver, the percent of the absorbed glucose retained by the liver was similar for control and with $\alpha$ - or $\beta$ blockade, but markedly decreased with combined blockade. Our conclusions are: $(a)$ phentolamine and propranolol effects on basal hepatic glucose production may predominantly reflect their action on insulin and glucagon secretion; (b) after oral glucose, $\alpha$ - and $\beta$-blockers separately or combined decrease glucose release into the portal system; $(c)$ net hepatic glucose uptake is predominantly determined by hyperglycemia but can be modulated by insulin and glucagon; $(d)$ direct correlation does not exist between hepatic delivery and uptake of insulin and net hepatic glucose uptake; $(e)$ alterations in oral glucose tolerance due to adrenergic blockers, beyond their effects on glucose absorption, can be, to a large extent, mediated by their effects on insulin and glucagon secretion reflecting both hepatic and peripheral glucose metabolism.
\end{abstract}

\section{Introduction}

Numerous studies have shown that glucagon and insulin are the most important factors regulating basal glucose production (1, 2). Adrenergic mechanisms, although potentially very effective, may not normally play an important role in modulating basal glucose production $(3,4)$ or during hyperglycemia after oral glucose (5). However, under some conditions, when catecholamine concentrations are elevated (6-8) or other mechanisms are deficient $(3,9,10)$, they may assume an important role that may be independent of insulin and glucagon. On the other hand,

Dr. Ishida's current address is Kagawa Medical School, 1750-1, Mikicho, Kita-Gun, Kagawa 76107, Japan. Address reprint requests to Dr. Field, Diabetes Research Center, St. Luke's Hospital, Department of Medicine, Division of Endocrinology \& Metabolism, Baylor College of Medicine, Houston, TX 77030.

Received for publication 9 October 1985.

J. Clin. Invest.

(C) The American Society for Clinical Investigation, Inc.

$0021-9738 / 86 / 04 / 1357 / 13 \$ 1.00$

Volume 77, April 1986, 1357-1369 many studies have shown that phentolamine (blocker of $\alpha$-adrenergic receptors) or propranolol (blocker of $\beta$-adrenergic receptors) affect insulin and glucagon secretion (11-13). Effects of such adrenergic blockade in the basal state and during hyperglycemia after intravenous glucose infusion have not always been consistent. Nevertheless, it is generally accepted that phentolamine stimulates insulin $(12,13)$ and glucagon (13) secretion, whereas propranolol inhibits insulin secretion $(12,14)$. During hyperglycemia produced by intravenous glucose, propranolol reduced while phentolamine had no effect on the increment of insulin secretion (15). In the basal state phentolamine and propranolol do not alter levels of epinephrine $(3,14)$. The increases in plasma norepinephrine after phentolamine, but not propranolol (3) and after water, mannitol, or xylose ingestion (5) were not associated with any change in hepatic glucose production or glucose levels unless insulin and/or glucagon levels were also altered $(3,13)$. The effects of propranolol and phentolamine, separately or combined, on hepatic glucose balance after oral glucose have not been examined previously. This was one aim of the present study; we also evaluated their effects on hepatic extractions of insulin and glucagon, glucose absorption, portal plasma flow, and total disposal of the glucose load. By changing the endogenous insulin and glucagon secretions, we were able to investigate their role in the regulation of net hepatic glucose uptake after oral glucose. The data indicate that insulin levels do not play an important role in modulating net hepatic glucose uptake, beyond their important effect on net hepatic glucose production, yet they do affect the total disposal of glucose.

\section{Methods}

\section{Animals and surgery}

Healthy adult male and female mongrel dogs weighing 16-34 kg were anesthetized with intravenous sodium phenobarbitol $(25 \mathrm{mg} / \mathrm{kg}$ body $\mathrm{wt})$ after an overnight fast $(18 \mathrm{~h})$. After a midline incision, pulsed rangegated ultrasonic Doppler flow probes were placed around the portal vein and the hepatic artery as described previously (16). Sampling microbore siliconized plastic catheters (Norton, Plastic and Synthetic Division, Akron, $\mathrm{OH}$ ) were positioned in the portal vein, femoral artery, and left common hepatic vein as reported previously (17). The portal vein sampling catheter lay immediately below the portal vein bifurcation. Left common hepatic vein catheterization was done through the superficial jugular vein using subdiaphragmatic control by hand. The tip of the one side-hole ( $3 \mathrm{~mm}$ from the tip) catheter was advanced $1.5-2.0 \mathrm{~cm}$ into the hepatic vein from the edge of the liver. Another microbore siliconized plastic catheter was inserted into the external jugular vein for the infusion of the adrenergic blockers. The free ends of the catheters and the wires of the Doppler flow probes were threaded through a long needle, which was routed subcutaneously to the back of the dog's neck and pushed out through the skin around the midline $5-10 \mathrm{~cm}$ below the base of the skull. Each catheter was flushed with heparin sodium $(50 \mathrm{U} / \mathrm{ml})$ and the ends were then closed with short stainless wire plugs. The catheters were flushed daily with $2 \mathrm{ml}$ heparinized saline $(50 \mathrm{U} / \mathrm{ml})$ to prevent throm- 
bosis. After at least 2 wk of recovery from surgery, experiments were done after an overnight fast in conscious, unrestrained dogs. The order of each experiment was random with an interval of at least $7 \mathrm{~d}$ between them. Experiments were done only on animals whose hematocrits were $>30 \%$ and who appeared in healthy condition with a good appetite and normal stools.

Phasic and mean control aortic blood pressure were measured with a Statham $\mathrm{P}^{23} \mathrm{db}$ pressure transducer (Statham Instruments, Inc., Oxnard, CA) connected to the arterial catheter. The blood pressure did not change significantly throughout each experiment, except for an initial transient increase with phentolamine and decrease with propranolol and an initial transient increase with the ingestion of glucose. Blood samples for glucose, insulin, and glucagon were obtained simultaneously from the femoral artery, portal vein, and hepatic vein, with continuous measurement of portal and hepatic vein blood flows.

\section{Experimental procedures}

Protocol I: control oral glucose group. In nine dogs, after a 30-min control period, $1.0 \pm 0.1 \mathrm{~g} / \mathrm{kg}$ body wt glucose ( $10 \%$ solution) was consumed within $1-2 \mathrm{~min}$. Blood samples were obtained at $-30,-20,-10,0,10,20,30$, 45, 60, 75, 90, 105, 120, 150, and $180 \mathrm{~min}$.

Protocol II: phentolamine and oral glucose group. In 10 dogs after a 30-min control period ( -60 to $-30 \mathrm{~min}$ ), phentolamine (Regitine; CIBA Pharmaceutical Company, Summit, NJ) was infused into the external jugular vein at a rate of $5 \mu \mathrm{g} / \mathrm{kg}$ per min from -30 to $120 \mathrm{~min}$ after a priming dose of $2 \mathrm{mg}$ at $-30 \mathrm{~min}$. Oral glucose $(1.0 \pm 0.1 \mathrm{~g} / \mathrm{kg})$ was consumed within 1-2 min at 0 time. Samples of blood were obtained at $-60,-50,-40,-30,-20,-10,0,10,20,30,45,60,75,90,105,120$, 150 , and $180 \mathrm{~min}$.

Protocol III: propranolol and oral glucose. In 10 dogs after a 30-min control period ( -60 to $-30 \mathrm{~min}$ ), propranolol (Inderal-Ayerst Laboratories, Inc., New York, NY) was infused into the external jugular vein at a rate of $7 \mu \mathrm{g} / \mathrm{kg}$ per min from -30 to $120 \mathrm{~min}$ after a priming dose of $4 \mathrm{mg}$ at $-30 \mathrm{~min}$. Glucose $(1.0 \pm 0.1 \mathrm{~g} / \mathrm{kg})$ was ingested within $1-2$ min at 0 time. Blood samples were obtained as in the phentolamine group.

Protocol IV: combined $\alpha$ - and $\beta$-blockade and oral glucose. In eight dogs after a 30 -min control period $(-60$ to $-30 \mathrm{~min})$, phentolamine and propranolol were infused together at the same rates as in protocols II and III, respectively, from -30 to $120 \mathrm{~min}$ after priming doses as above. Glucose $(1.0 \pm 0.1 \mathrm{lg} / \mathrm{kg})$ was ingested within $1-2 \mathrm{~min}$ at 0 time. Blood samples were obtained as in protocol II.

\section{Analysis}

Blood flow was measured with an ultrasonic range-gated pulsed Doppler flow meter designed by Hartley et al. $(18,19)$ and as described elsewhere (16). The blood flow measurements were corrected to plasma flow based on hematocrits obtained every $\mathbf{3 0}$ min since glucose, insulin, and glucagon were measured in plasma. Blood samples were collected in chilled tubes containing $500 \mathrm{U}$ Trasylol (FBA Pharmaceutical, Inc., New York) and $1.2 \mathrm{mg}$ EDTA $/ \mathrm{ml}$ of blood. Plasma immunoreactive insulin was assayed using dextran-coated charcoal (20). Plasma immunoreactive glucagon was assayed with Unger's 30K antibody (21). Plasma glucose was measured by a glucose autoanalyzer (Beckman Instruments, Inc., Fullerton, CA), using a glucose oxidase method.

\section{Calculations}

The flux of glucose and hormones in each vessel was determined by multiplying plasma flow by plasma concentration. Hepatic vein plasma flow was the sum of the plasma flows in the portal vein and hepatic artery. The amount of glucose and hormones presented to the liver was the sum of the contribution from the portal vein and hepatic artery (concentration $\times$ flow). The amount leaving the liver was the product of hepatic vein concentration times hepatic vein plasma flow. The fractional hepatic extraction of hormones was calculated according to the formula: [hormone presented to the liver - hormone leaving the liver] $\times 100$ /hormone presented to the liver.
The calculation of the mean value of the hepatic extraction of hormones was based on the percentage of hormones extracted in each individual dog and not the mean amounts of hormones reaching and leaving the liver that are presented in the figures.

The absorption of glucose into the portal system was calculated according to the formula: [(portal vein glucose - arterial glucose) $\times$ portal flow]/body wt.

A positive result indicates net absorption into the portal system, while a negative one indicates extra hepatic splanchnic glucose uptake. Total absorption was the area above the zero line over $180 \mathrm{~min}$. The net hepatic glucose balance was determined as follows: [(glucose leaving the liver) - (glucose presented to the liver)]/body wt.

A positive balance indicates hepatic glucose output, whereas a negative one connotes hepatic glucose uptake. Total net hepatic glucose uptake was the integrated area below the zero line from the time net hepatic uptake occurred until the time it ceased. Net splanchnic glucose balance was calculated by the following formula: [(hepatic vein glucose - arterial glucose) $X$ hepatic flow]/body wt.

Net residual or renewed endogenous glucose output was calculated as follows: [(net hepatic glucose uptake + net splanchnic glucose output) - (net absorption)]/body wt.

Positive values of net hepatic glucose uptake were used for this calculation. The data are presented as means \pm SEM. The basal value was the mean $\pm S E M$ of the four values obtained from -30 to $0 \mathrm{~min}$ in protocol I, whereas in protocols II, III, and IV the basal values were obtained from -60 to $-30 \mathrm{~min}$. The subsequent three values from -20 to $0 \mathrm{~min}$ served in those groups as a control period for effects of the $\alpha$ and $\beta$ blockers alone. Analysis of variance for repeated measurement was used for statistical analysis of the fluctuations within a group from the basal value or the period of infusion of the blockers alone. Differences in mean values between groups were detected by the unpaired $t$ test. $P$ values $<0.05$ were considered to be significant.

\section{Results}

Plasma flows. Basal portal vein plasma flow was $16.2 \pm 0.6 \mathrm{ml} /$ kg per min in all four groups (Fig. 1). The hepatic artery plasma flows were $4.4 \pm 0.3 \mathrm{ml} / \mathrm{kg}$ per $\mathrm{min}$ and the hepatic vein plasma flows were $20.5 \pm 0.7 \mathrm{ml} / \mathrm{kg}$ per min. The differences in the values of all four groups in all the blood vessels were not statistically significant. Phentolamine infusion and combined blockade had no significant effect on flows in any of the three vessels, while propranolol suppressed portal vein plasma flows from 15.6 \pm 1.8 to $14.1 \pm 1.7 \mathrm{ml} / \mathrm{kg}$ per min. The significant increase in portal vein plasma flow associated with oral glucose was markedly diminished by phentolamine, propranolol, and the combined blockade. In the propranolol group, portal vein plasma flow did not exceed the basal value, while with combined blockade portal and hepatic vein plasma flows decreased significantly below basal at $75 \mathrm{~min}$. The hepatic artery plasma flows did not change significantly from the basal state after oral glucose with or without the $\alpha$ or $\beta$ blockers, separately or combined.

Plasma glucose concentrations. Hepatic vein glucose concentrations significantly exceeded both the arterial and portal vein glucose levels during the basal period (Fig. 2). The average values of all four groups were $91 \pm 1,82 \pm 2$, and $81 \pm 2 \mathrm{mg} / 100$ $\mathrm{ml}$ in the hepatic vein, artery, and portal vein, respectively. The infusion of phentolamine alone decreased plasma glucose levels. In contrast, the glucose levels were significantly increased during the infusion of propranolol alone $(12 \mathrm{mg} / 100 \mathrm{ml}$ in the hepatic vein, $7 \mathrm{mg} / 100 \mathrm{ml}$ in the artery, and $5 \mathrm{mg} / 100 \mathrm{ml}$ in the portal vein). A similar effect to that of propranolol was observed with the infusion of both blockers. After the administration of oral glucose, the glucose concentration increased significantly above 
A

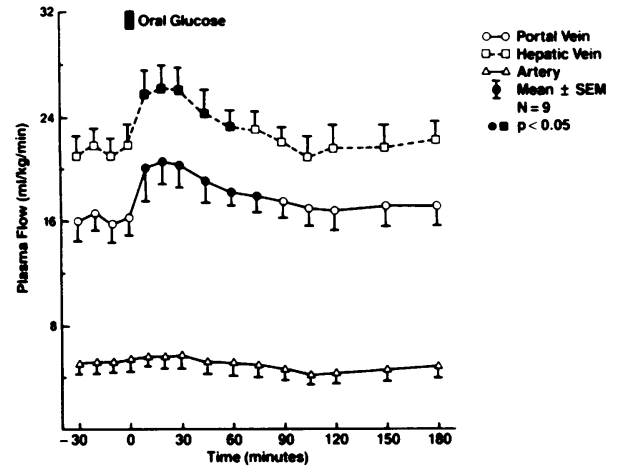

C

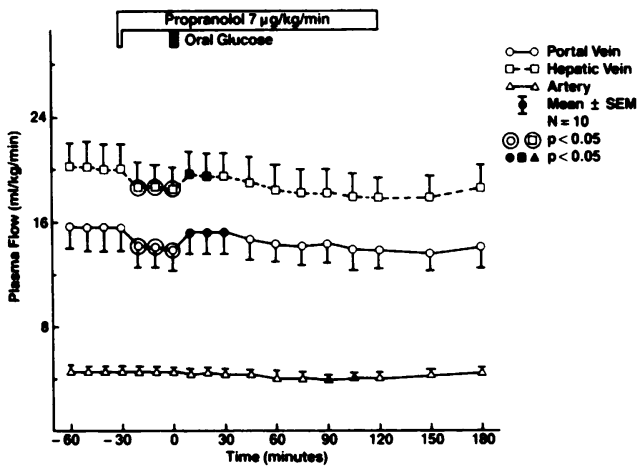

Figure 1. The changes in plasma flow of the portal vein, 0 ; hepatic vein, $\square$; and hepatic artery, $\Delta$; during the basal state \pm phentolamine or propranolol, separately or combined, and after oral glucose administration \pm phentolamine or propranolol separately or combined. Control oral glucose $(A),+$ phentolamine $(B)+$ propranolol $(C)+$ com-

basal in all three vessels in all four groups. In the control group (group I) the portal glucose concentration increased to a peak value of $183 \pm 14 \mathrm{mg} / 100 \mathrm{ml}$ at $30 \mathrm{~min}$, similar to $197 \pm 14 \mathrm{mg} /$ $100 \mathrm{ml}$ at $30 \mathrm{~min}$ in group II, $196 \pm 9 \mathrm{mg} / 100 \mathrm{ml}$ in group III at $45 \mathrm{~min}$, and $217 \pm 22 \mathrm{mg} / 100 \mathrm{mg}$ in group IV at $45 \mathrm{~min}$. In the control group plasma glucose levels returned to basal at $137 \pm 12$ $\mathrm{min}$, at $135 \pm 13 \mathrm{~min}$ in the propranolol group, and significantly earlier at $93 \pm 6$ min with phentolamine. Combined blockade with oral glucose resulted in the most delayed return to basal at $154 \pm 12 \mathrm{~min}$. These values were calculated based on the time that glucose returned to basal in each individual dog and not by the average concentrations shown in Fig. 2.

Net glucose release into the portal system. During the basal state there was net uptake of glucose by the extrahepatic splanchnic tissues of $0.4 \pm 0.1 \mathrm{mg} / \mathrm{kg}$ per $\mathrm{min}$ in all four groups (Fig. 3). This uptake accounts for $21 \%$ of the net hepatic glucose production in the basal state (Fig. 4). Immediately after oral glucose administration, net glucose absorption into the portal system occurred, which throughout the experiment, was greater in the control group than in groups II, III, and IV. Of the total glucose ingested in the control group, $77 \pm 4 \%$ was released into the portal system during the ensuing $180 \mathrm{~min}$. At this time an average of $0.8 \pm 6 \mathrm{mg} / \mathrm{kg}$ per min glucose was still being absorbed. Only $54 \pm 3 \%$ of the glucose load was absorbed into the portal system in the presence of phentolamine and at $180 \mathrm{~min} 0.4 \pm 0.3$ $\mathrm{mg} / \mathrm{kg}$ per min glucose was still being absorbed. With propranolol $59 \pm 6 \%$ of the load appeared in the portal vein and the absorption

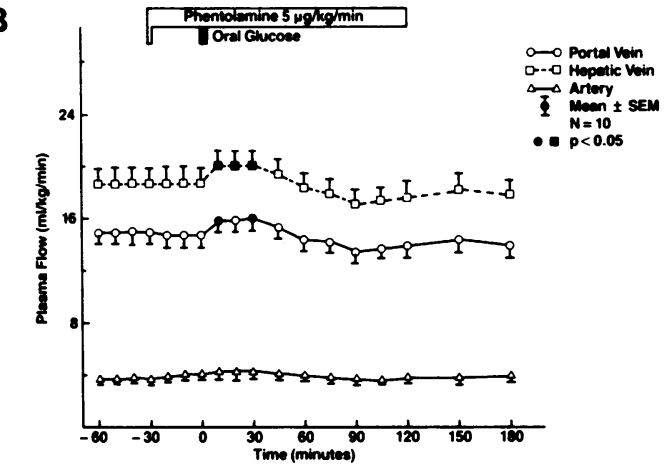

D

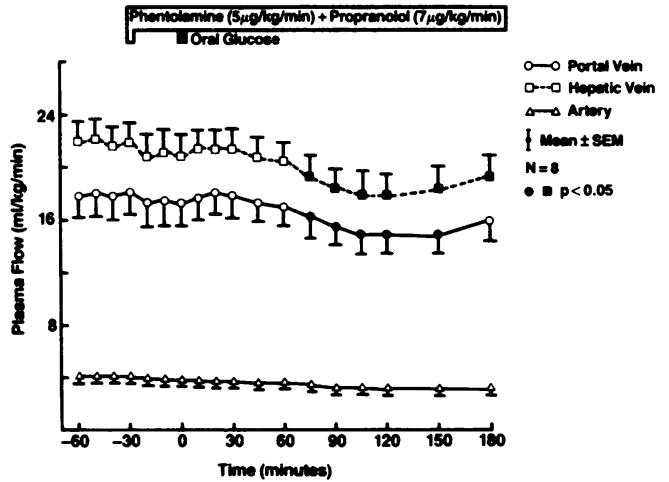

bined blockade $(D)$. Circled symbols represent significant difference from the basal state in each experiment, $P<0.05$. Closed symbols indicate significant difference from the basal period of infusion of the $\alpha$ and $\beta$-blockers, separately or combined, and before the administration of oral glucose, $P<0.05$.

ceased at $150 \pm 9 \mathrm{~min}$ (Fig. 3). With combined blockade $62 \pm 5 \%$ of the glucose load was absorbed and at $180 \min 0.5 \pm 0.5 \mathrm{mg} /$ kg per min was still released into the portal system.

Net hepatic and splanchnic glucose balance. The basal net hepatic glucose production of all four groups averaged $1.9 \pm 0.2$ $\mathrm{mg} / \mathrm{kg}$ per min (Fig. 4). The net splanchnic glucose balance was $0.4 \pm 0.1 \mathrm{mg} / \mathrm{kg}$ per min less. The infusion of phentolamine decreased glucose output from $1.7 \pm 0.2$ to $1.3 \pm 0.3 \mathrm{mg} / \mathrm{kg}$ per min. Although statistically this is not significantly different, during the same period the plasma glucose levels in all three vessels decreased below basal concentrations (Fig. 2). In contrast, propranolol infusion significantly increased net hepatic glucose production from $1.7 \pm 0.2$ to $2.5 \pm 0.4 \mathrm{mg} / \mathrm{kg}$ per min, commensurate with the increase in plasma glucose (Fig. 2). Combined blockade increased net basal glucose output from $2.4 \pm 0.2$ to $2.9 \pm 0.4 \mathrm{mg} / \mathrm{kg}$ per min, consistent with the significantly increased plasma glucose levels (Fig. 2). The splanchnic glucose balance changed parallel to the hepatic glucose production during the infusion of the adrenergic blockers alone (Fig. 4). After the administration of oral glucose the liver rapidly changed from net output to net uptake in all four groups (shaded area in Fig. 4). The magnitude of net hepatic glucose uptake was greater in the control oral glucose group with a maximal value of $-4.4 \pm 0.6$ $\mathrm{mg} / \mathrm{kg}$ per min at $45 \mathrm{~min}$, compared with $-2.4 \pm 0.7$ and $-2.7 \pm 0.5 \mathrm{mg} / \mathrm{kg}$ per min in groups II and III, respectively. The lowest net uptake was observed with the combined blockade, $-1.1 \pm 0.6 \mathrm{mg} / \mathrm{kg}$ per min. Overall, $40 \pm 6 \%$ of the glucose that 
A

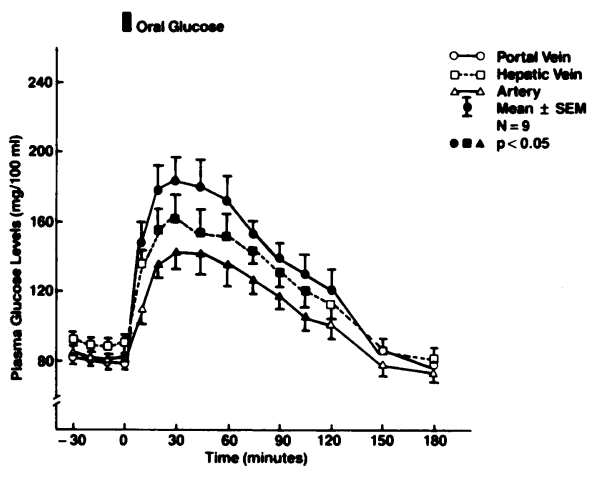

C

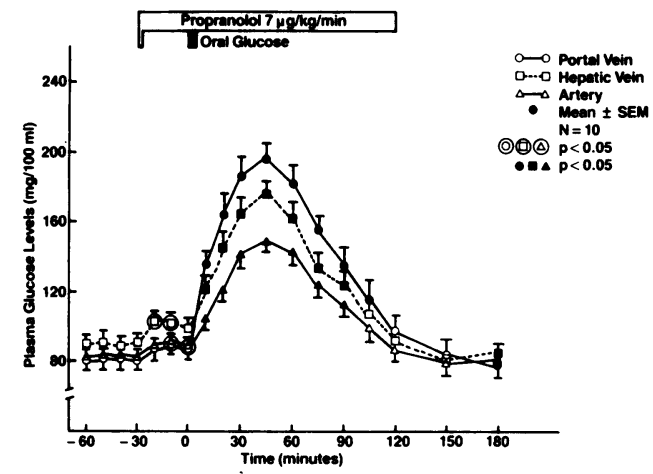

B
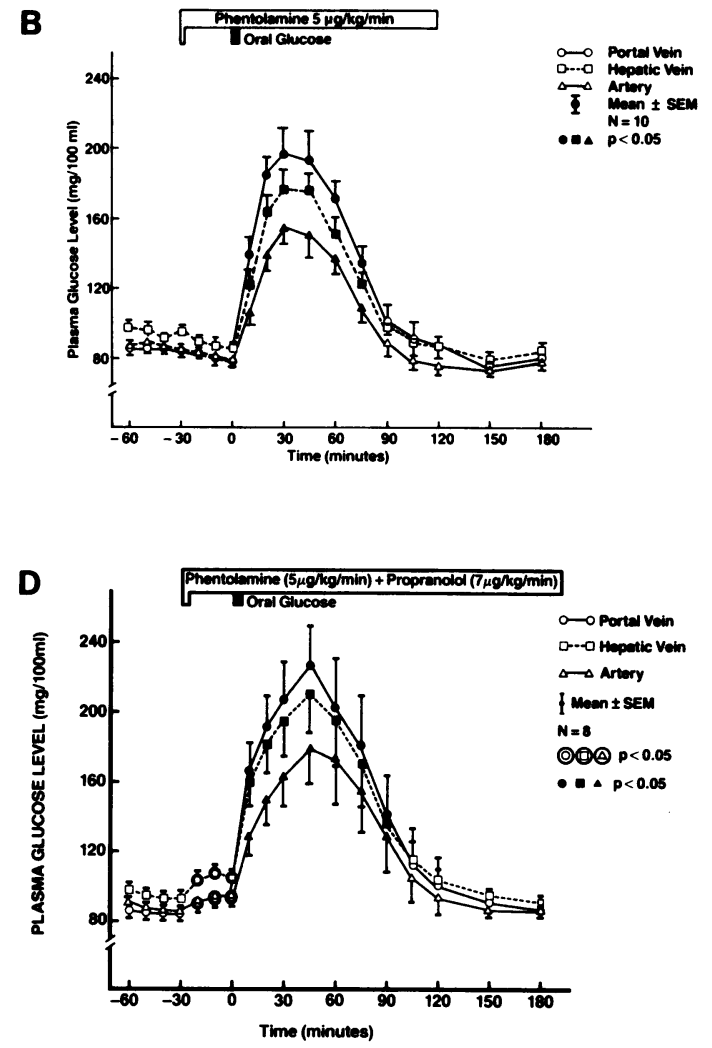

Figure 2. The changes in plasma glucose levels in the portal vein; $\circ$; hepatic vein, $\square$; and artery, $\Delta$; during the basal state \pm phentolamine or propranolol separately or combined. Control oral glucose $(A),+$ phentolamine $(B),+$ propranolol $(C)$ and + combined blockade (D). Circled and closed symbols as in Fig. 1.

A

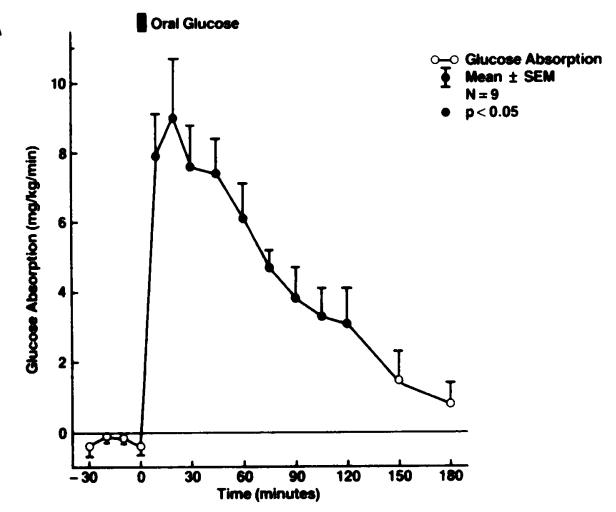

C

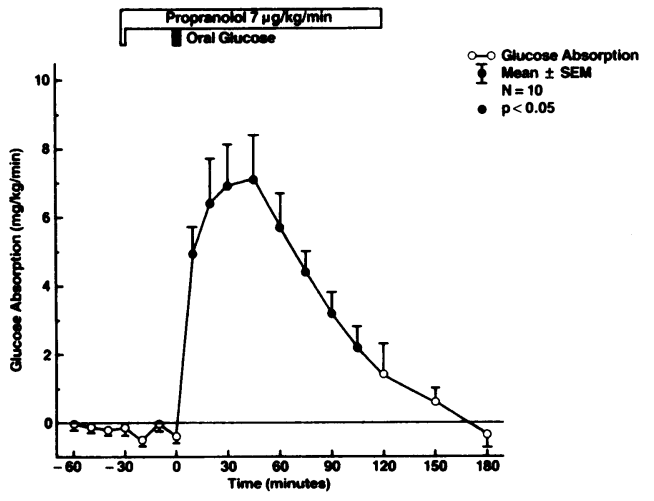

B

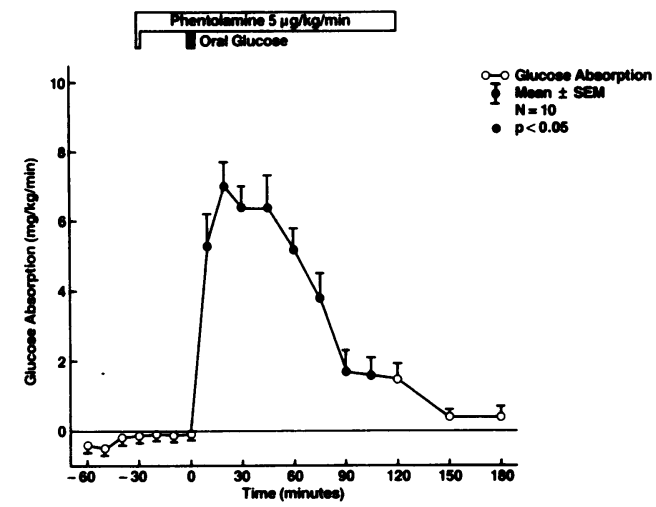

D

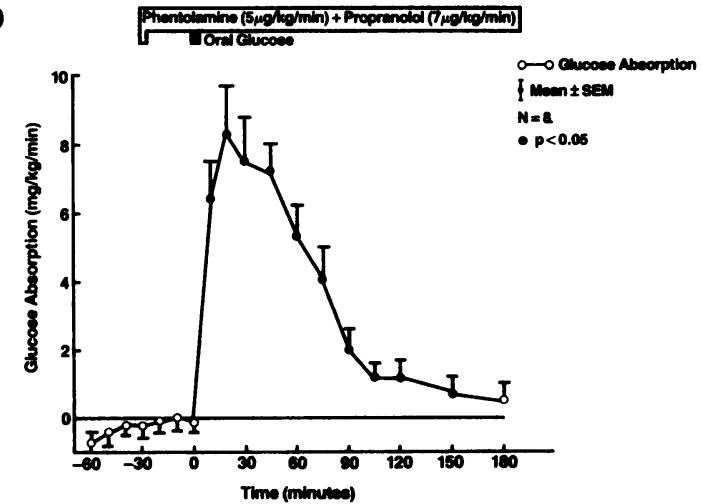

Figure 3. The rate of net glucose absorption into the portal system before and after glucose administration \pm phentolamine or propranolol, separately or combined. Control oral glucose $(A),+$ phentolamine $(B),+$ propranolol $(C)$ and + combined blockade (D). Closed symbols as in Fig. 1. 
A

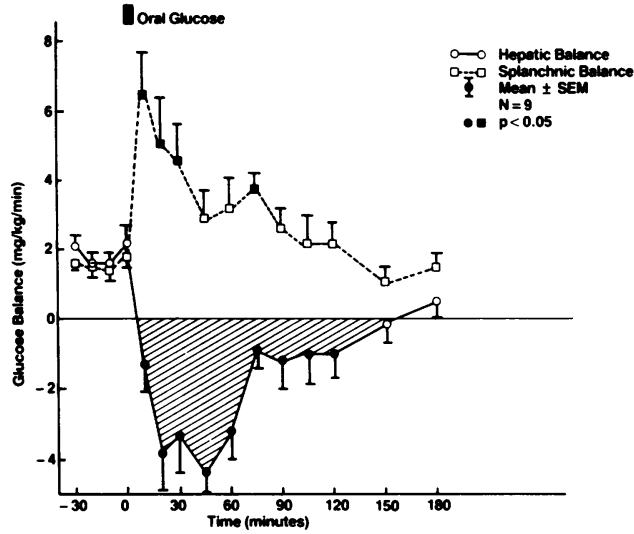

C

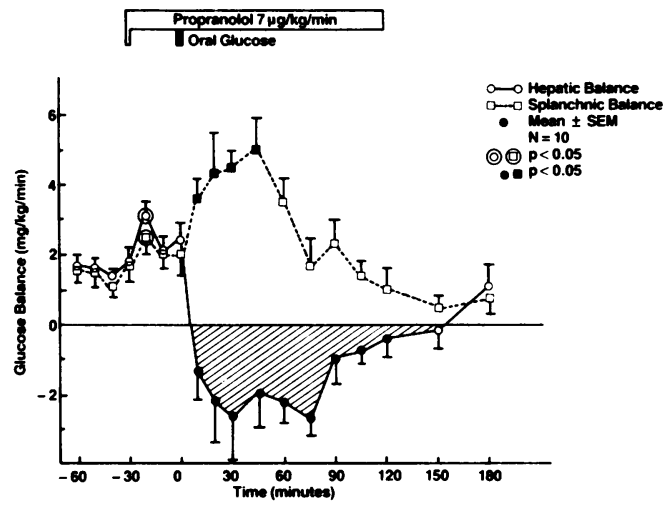

B

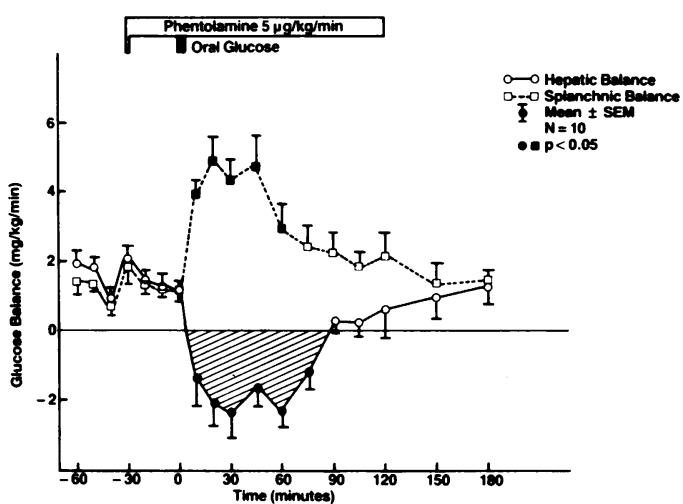

D

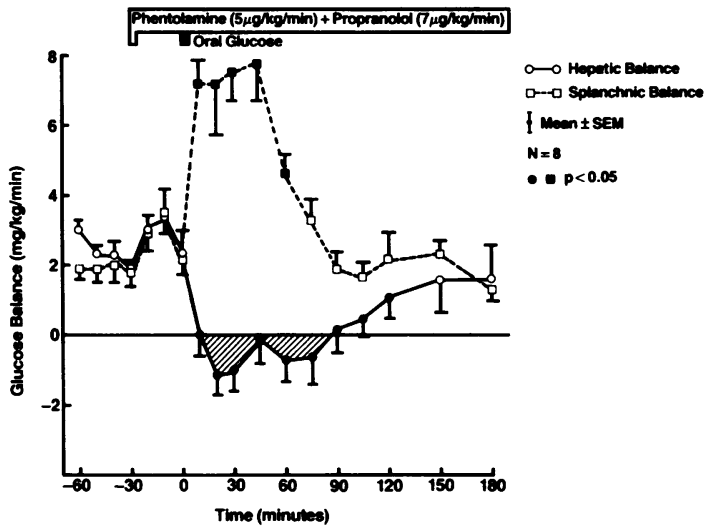

Figure 4. The changes in net hepatic, $O$; and splanchnic, $\square$; glucose balances before and after oral glucose administration \pm phentolamine and propranolol, separately or combined. Control oral glucose $(A),+$ phentolamine $(B),+$ propranolol $(C)$ and + combined blockade $(D)$. Circled and closed symbols as in Fig. 1.

was absorbed into the portal system was taken up by the liver in the control group, not significantly different from the $34 \pm 6 \%$ that was retained by that organ in group II or $43 \pm 6 \%$ during the infusion of propranolol. However, combined adrenergic blockade significantly reduced the portion of the absorbed glucose removed by the liver to $13 \pm 4 \%$. Net hepatic glucose uptake ceased at $139 \pm 16 \mathrm{~min}$ in the control group, at $145 \pm 10 \mathrm{~min}$ with propranolol, at $105 \pm 10 \mathrm{~min}$ in the presence of phentolamine, and at $90 \pm 12$ with combined blockade. The average times in groups II and IV are significantly earlier compared with group III. When the comparison is based on the average uptake of all the dogs in a group as shown in Fig. 4, hepatic glucose uptake ceased significantly earlier in group II and IV than in both I and III. Net splanchnic glucose balance increased significantly above baseline after the administration of the oral glucose in all groups (Fig. 4). The splanchnic glucose balance was the difference between the amount of glucose absorbed and the amount taken up by the liver as long as net hepatic glucose uptake took place (Table I). There was no residual glucose output from an endogenous glucose source and the basal glucose production was suppressed to 0 in groups I, II, and III. Endogenous residual glucose output ceased later only in the presence of both blockers and resumed earlier as with $\alpha$-blocker alone, consistent with the lower total and lower magnitude of the net hepatic glucose uptake in this group (IV). Resumption of endogenous glucose output occurred despite continuing glucose absorption in the control, $\alpha$ blocker, and combined blockade groups but not in the $\beta$-blocker group. Thus, the glucose released from the splanchnic bed, after net hepatic glucose uptake ceased, contained both endogenous and exogenous glucose in these three groups. Since the output of glucose in the $\beta$-blocker group resumed after glucose absorption ceased, the source in terms of net balance in this group was endogenous only.

Plasma insulin levels and balance across the liver. Basal portal vein plasma insulin levels were similar in all four groups, $31 \pm 5$ $\mu \mathrm{U} / \mathrm{ml}, 37 \pm 6,36 \pm 6$, and $35 \pm 6 \mu \mathrm{U} / \mathrm{ml}$ in the control, $\alpha$ - and $\beta$ adrenergic and combined $\alpha$ - and $\beta$-blockade groups, respectively (Fig. 5). The infusion of phentolamine for 30 min significantly increased portal insulin to an average of $78 \pm 13 \mu \mathrm{U} / \mathrm{ml}$, whereas propranolol significantly decreased it to $12 \pm 2 \mu \mathrm{U} / \mathrm{ml}$. Portal vein plasma insulin did not change after combined $\alpha$ - and $\beta$ blockade. Parallel and significant changes occurred in the hepatic vein and arterial insulin levels during the infusion of the adrenergic blockers (Fig. 5). After oral glucose the portal vein insulin levels significantly increased above basal to a peak value of $173 \pm 52 \mu \mathrm{U} / \mathrm{ml}$ at $30 \mathrm{~min}$ in the control group and then returned to basal at $180 \mathrm{~min}$. During the infusion of phentolamine, oral glucose administration caused a greater increase than in the control group throughout the experiment. The portal vein peak value at $30 \mathrm{~min}$ was $363 \pm 87 \mu \mathrm{U} / \mathrm{ml}$, whereas the arterial peak was $106 \pm 25 \mu \mathrm{U} / \mathrm{ml}$ compared with $48 \pm 13 \mu \mathrm{U} / \mathrm{ml}$ in the control group. Oral glucose administration combined with the infusion of propranolol caused significantly smaller increments in insulin levels in all three blood vessels which occurred later as compared with both the control and $\alpha$-blocker groups. The portal vein insulin peaked at $86 \pm 19 \mu \mathrm{U} / \mathrm{ml}$ at $75 \mathrm{~min}$, which is lower and 


\begin{tabular}{|c|c|c|c|c|}
\hline Time & Oral glucose & $\begin{array}{l}\text { Oral glucose } \\
+ \text { phentolamine }\end{array}$ & $\begin{array}{l}\text { Oral glucose } \\
+ \text { propranolol }\end{array}$ & $\begin{array}{l}\text { Oral glucose } \\
+ \text { combined blockade }\end{array}$ \\
\hline $\min$ & & $\mathrm{mg} / \mathrm{kg}$ per min & & \\
\hline-60 to -30 & & $1.7 \pm 0.2$ & $1.7 \pm 0.2$ & $2.4 \pm 0.2$ \\
\hline-30 to 0 & $1.9 \pm 0.2$ & $1.3 \pm 0.3$ & $2.5 \pm 0.4^{*}$ & $2.9 \pm 0.4$ \\
\hline 10 & -0.1 & 0 & 0 & 0.8 \\
\hline 20 & 0 & 0 & 0.1 & 0 \\
\hline 30 & 0.3 & 0.3 & 0.2 & 1.0 \\
\hline 45 & -0.1 & -0.1 & -0.2 & 0.6 \\
\hline 60 & 0.3 & 0 & 0 & 0 \\
\hline 75 & -0.1 & -0.2 & 0 & -0.2 \\
\hline 90 & 0 & $0.5 \ddagger$ & 0 & -0.1 \\
\hline 105 & -0.1 & 0.2 & -0.1 & $0.5 \ddagger$ \\
\hline 120 & 0.1 & 0.6 & 0 & 1.0 \\
\hline 150 & -0.1 & 0.9 & 0.1 & 1.6 \\
\hline 180 & $0.7 \ddagger$ & 1.0 & $1.0 \ddagger$ & 0.0 \\
\hline
\end{tabular}

Phentolamine ( $5 \mu \mathrm{g} / \mathrm{kg}$ per $\mathrm{min}$ ) or propranolol $(7 \mu \mathrm{g} / \mathrm{kg}$ per $\mathrm{min}$ ) was infused intravenously from -30 to $120 \mathrm{~min}$. Oral glucose ( $1 \mathrm{~g} / \mathrm{kg})$ was administered at $0 \mathrm{~min}$. The endogenous glucose output in terms of net balance was calculated by the equation: (Net hepatic glucose uptake + net splanchnic glucose output) - net glucose absorption. * Indicates significant difference from basal, $P<0.05$. $¥$ Indicates the time net endogenous glucose output resumed.

later than in groups I and II (Fig. 5). Combined $\alpha$ - and $\beta$-adrenergic blockade after oral glucose diminished the insulin increment as compared with control; however, this difference was not statistically significant. The insulin concentrations of this group (IV) were significantly higher at 10,20 , and $30 \mathrm{~min}$ as compared with group III and significantly lower as compared
A

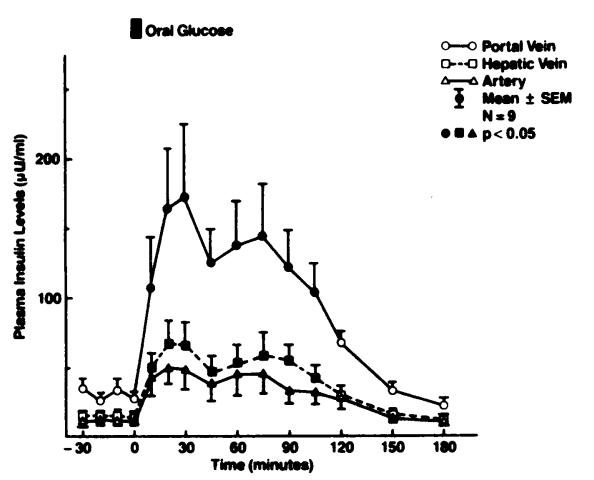

C

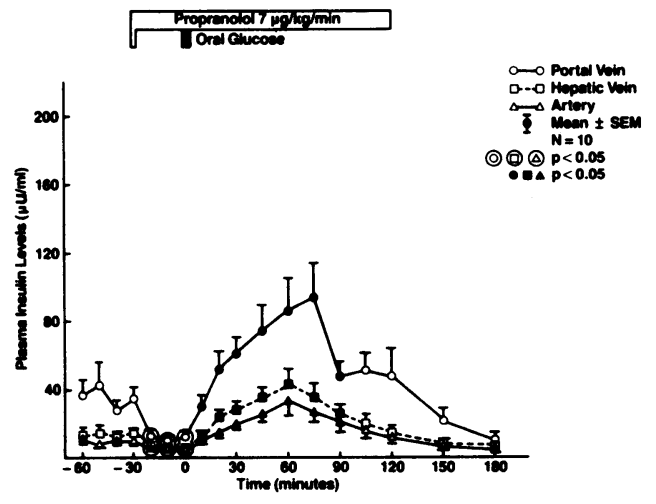

$\mathbf{B}$

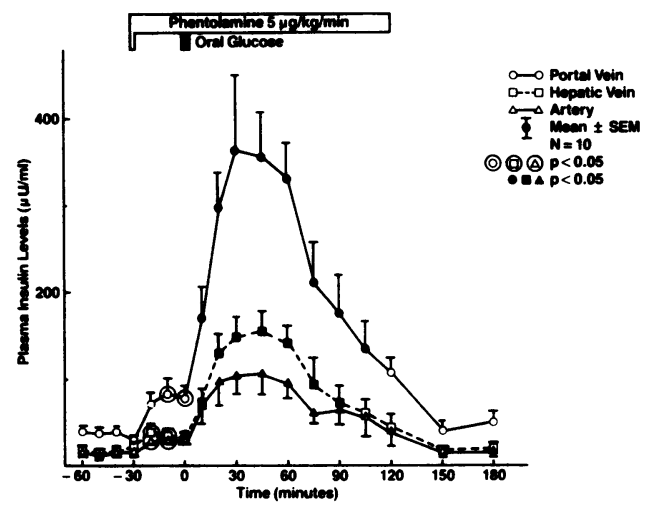

D

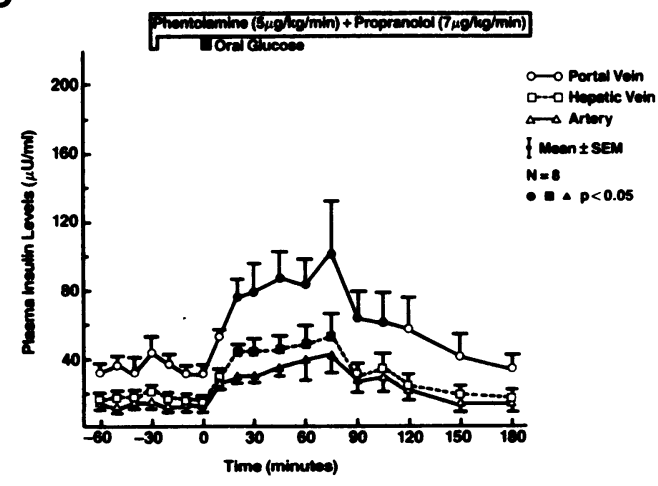

Figure 5. The changes in plasma insulin levels in the portal vein, 0 ; hepatic vein, $\square$; and artery, $\Delta$; before and after oral glucose administration \pm phentolamine and propranolol, separately or combined. Control oral glucose $(A)$, + phentolamine $(B),+$ propranolol $(C)$ and + combined blockade $(D)$. Circled and closed symbols as in Fig. 1. 
with group II. The amounts of insulin reaching the liver during the basal state were similar in all four groups, $0.5-0.7 \mathrm{mU} / \mathrm{kg}$ per min (Table II). The infusion of phentolamine significantly increased it to $1.2 \pm 0.2 \mathrm{mU} / \mathrm{kg}$ per min whereas propranolol significantly decreased it to $0.17 \pm 0.02 \mathrm{mU} / \mathrm{kg}$ per min. No significant change occurred with the combined infusion of $\alpha$ - and $\beta$-blockers. The amounts of insulin leaving the liver during the basal period were $\sim 0.3-0.4 \mathrm{mU} / \mathrm{kg}$ per $\mathrm{min}$ in all four groups. The infusions of phentolamine and propranolol caused changes that were parallel to the changes in the amounts of insulin reaching that organ. Oral glucose significantly increased the amount of insulin reaching and leaving the liver in all four groups. However, marked differences in the magnitude were observed. In the control group the amount of insulin presented to the liver peaked at $3.5 \pm 0.9 \mathrm{mU} / \mathrm{kg}$ per $\mathrm{min}$ and the amount leaving the liver peaked at $1.8 \pm 0.4 \mathrm{mU} / \mathrm{kg}$ per min. The total increment above basal over $180 \mathrm{~min}$ was $250 \pm 46 \mathrm{mU} / \mathrm{kg}$ to the liver and $115 \pm 21$ $\mathrm{mU} / \mathrm{kg}$ from the liver. Oral glucose combined with $\alpha$-blocker resulted in a greater stimulation of insulin to a peak of $6.4 \pm 1.7$ $\mathrm{mU} / \mathrm{kg}$ per min reaching the liver and $3.0 \pm 0.5 \mathrm{mU} / \mathrm{kg}$ per min leaving that organ. The total increment above basal was $443 \pm 60$ $\mathrm{mU} / \mathrm{kg}$ per $3 \mathrm{~h}$ to the liver and $210 \pm 26 \mathrm{mU} / \mathrm{kg}$ per $3 \mathrm{~h}$ from the liver. These amounts are significantly greater than the amounts in the control group. With propranolol the peak insulin value to the liver was $1.5 \pm 0.3 \mathrm{mU} / \mathrm{kg}$ per min and $0.8 \pm 0.2 \mathrm{mU} /$ $\mathrm{kg}$ per min from the liver. The total increments above basal over $180 \mathrm{~min}$ were $58 \pm 25 \mathrm{mU} / \mathrm{kg}$ to the liver and $34 \pm 12 \mathrm{mU} / \mathrm{kg}$ leaving it, markedly below the increments in groups I and II. Combined blockade resulted in intermediate values between the control and $\beta$-blocker groups, with $126 \pm 43 \mathrm{mU} / \mathrm{kg}$ per $3 \mathrm{~h}$ reaching the liver and $70 \pm 20 \mathrm{mU} / \mathrm{kg}$ per $3 \mathrm{~h}$ leaving that organ. These values were statistically not significantly different from groups I and II but significantly below those with phentolamine (Table II).

Plasma glucagon levels and balance across the liver. The infusion of $\alpha$-blocker alone significantly increased basal glucagon levels from $297 \pm 46 \mathrm{pg} / \mathrm{ml}$ to $407 \pm 80 \mathrm{pg} / \mathrm{ml}$ in the portal vein (Fig. 6). Propranolol alone had no significant effect on glucagon concentrations. Combined blockade significantly increased basal portal vein glucagon levels from $451 \pm 59 \mathrm{pg} / \mathrm{ml}$ to $601 \pm 71 \mathrm{pg} /$ $\mathrm{ml}$. Oral glucose suppressed glucagon levels similarly in all the vessels in groups I, II, and III while combined blockade caused less suppression, consistent with the delayed and smaller net hepatic glucose uptake and higher splanchnic glucose output. However, glucagon levels tended to return toward basal significantly earlier, at $75 \mathrm{~min}$ in the presence of phentolamine as compared with groups I, III, and IV.

Hepatic extraction of insulin and glucagon. The basal fractional hepatic extraction of insulin was similar at $43 \pm 4 \%, 50 \pm 6 \%$, $53 \pm 5 \%$, and $40 \pm 7 \%$ in groups I, II, III, and IV, respectively (Fig. 7). The infusion of phentolamine, propranolol, or combined blockade did not change it significantly. After oral glucose the fractional hepatic extraction of insulin significantly increased in the control group to $59 \pm 4 \%$ and $55 \pm 5 \%$ at 45 and $60 \mathrm{~min}$, respectively. No significant change was observed when oral glucose was administered with $\alpha, \beta$, or combined blockade. The basal fractional hepatic extraction of glucagon was similar in all four groups: $16 \pm 3 \%$ in the control group; $20 \pm 5 \%$ in the $\alpha$-blocker group, $18 \pm 3$ in the $\beta$-blocker one, and $24 \pm 7$ with combined adrenergic blockade (Fig. 7). It was not changed by adrenergic blockade. Oral glucose alone or together with propranolol or combined $\alpha$-and $\beta$-blockade did not modify glucagon extraction.
Compared with phentolamine alone, oral glucose and the $\alpha$ blocker increased fractional hepatic extraction of glucagon but the values were not significantly different from basal.

Insulin/glucagon molar ratio. The basal insulin/glucagon molar ratio in the portal vein of the control group was $2.1 \pm 0.1$ and not significantly different from the basal ratios in groups II, III, and IV; $2.7 \pm 0.3,2.5 \pm 0.3$, and $1.9 \pm 0.4$ respectively. During the infusion of phentolamine the ratio significantly increased to $3.9 \pm 0.2$ compared with the marked decrease during the infusion of propranolol, $0.7 \pm 0.1$. During combined blockade the ratio decreased to $1.5 \pm 0.4$. After oral glucose the insulin/glucagon molar ratio significantly increased in all four groups; however, the increase was significantly greater in the $\alpha$-blocker group with peak value of $48.1 \pm 7.8$ compared with that in the control group, $19.4 \pm 4.2$, the $\beta$-blocker group, $11.6 \pm 2.6$, and the combined blockade, $6.6 \pm 1.5$.

\section{Discussion}

The stimulatory effect of phentolamine on basal insulin and glucagon and the inhibitory action of propranolol on insulin levels, which were evident in the portal vein, hepatic vein, and artery, confirm previous results of others (11-13). However other investigators have failed to observe such effects of phentolamine and/or propranolol in sheep (22), dogs (23), or humans $(13,24)$. Such differences might reflect the amount of phentolamine and propranolol administered, the site of sampling or different species although controversial results have been reported within the same species. Measurements in the portal vein in our study maximize the effects since it permits more direct assessment of pancreatic islet secretion. Changes in hepatic extraction of insulin as well as effects of dilution may minimize differences when only peripheral hormone levels are obtained.

The changes in basal insulin and glucagon observed with adrenergic blockade can account for the alterations in the plasma glucose and hepatic glucose production. These reflect the well established action of insulin to suppress $(1,2,25)$ and glucagon to stimulate $(1,2)$ hepatic glucose production. This relationship is supported by those studies in which phentolamine and propranolol did not modify insulin and glucagon concentrations since no changes in glucose levels were observed (13, 22-24). In our study phentolamine increased insulin more than glucagon, causing a significant increase in the insulin/glucagon molar ratio and a net effect to suppress hepatic glucose production. Propranolol markedly changed this ratio in the opposite direction since insulin secretion was suppressed with no change in glucagon. The ratio decreased with the combined blockade as well, however, in this case insulin levels did not change, while glucagon was increased. The correlation between the insulin/glucagon molar ratio and hepatic glucose production has been repeatedly documented $(13,26,27)$. Since phentolamine and propranolol do not change basal growth hormone and cortisol levels (3), it is unlikely, but not excluded, that these hormones are responsible for the changes in hepatic glucose production. Even if growth hormone and cortisol were increased, their contribution to the effects we observed would be minimal since they require several hours for their action (28). In the basal state phentolamine and propranolol do not alter epinephrine levels $(3,14)$ and propranolol does not change norepinephrine $(3,14)$. Although phentolamine augmented norepinephrine, this was not associated with any change in plasma glucose levels, glucose production, or glucose utilization (3). Furthermore, our conclusion concerning the 


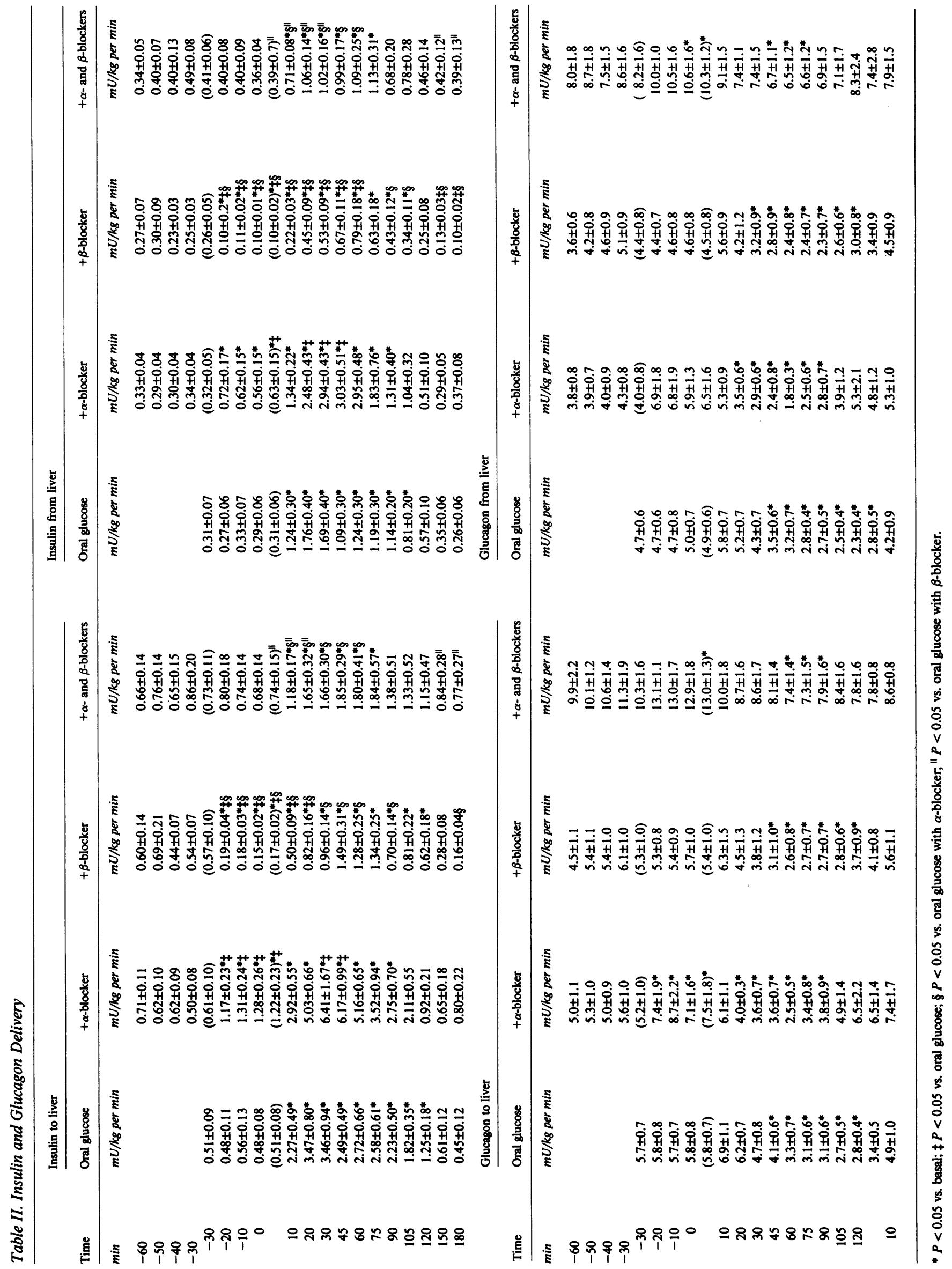


A

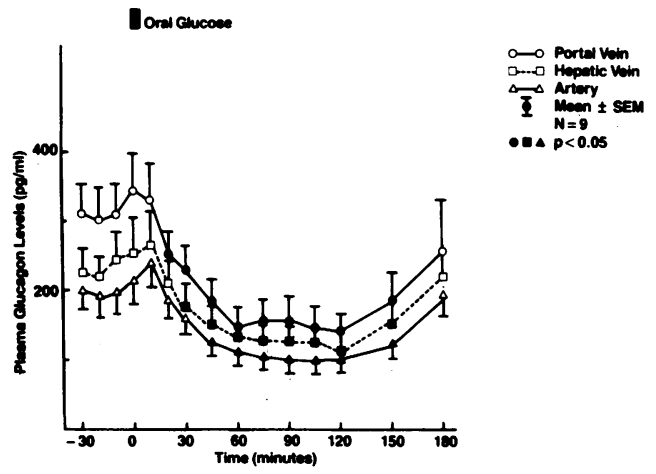

C

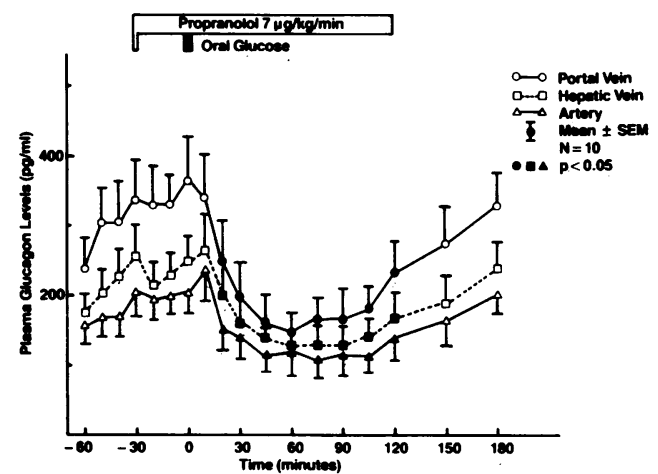

B

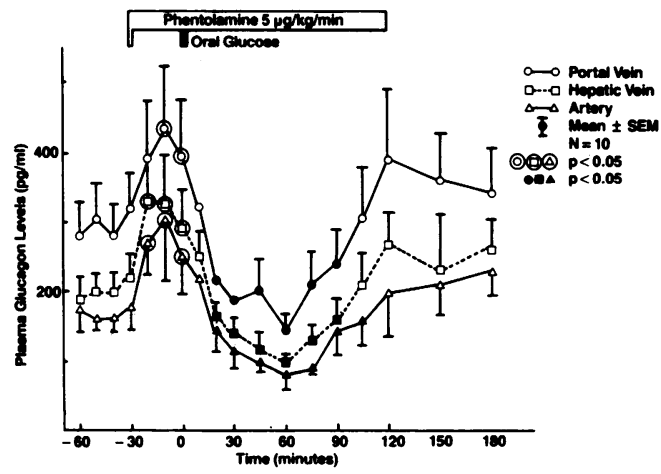

D

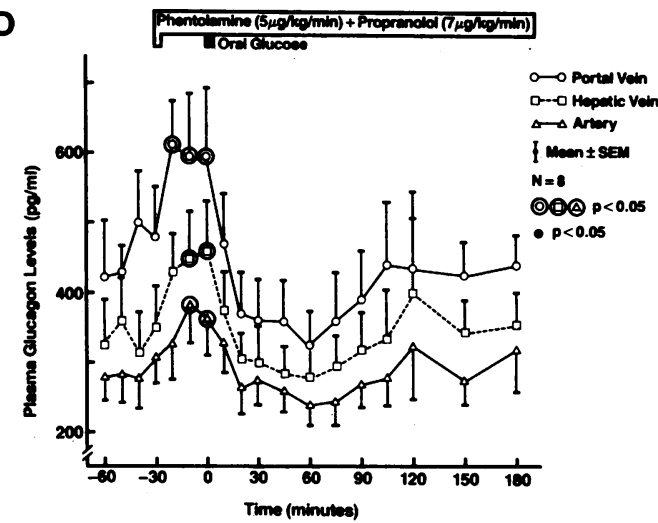

Figure 6. The changes in plasma glucagon levels in the portal vein, $\circ$; hepatic vein, $\square$; and artery, $\triangle$; before and after oral glucose administration \pm phentolamine and propranolol, separately or combined. Control oral glucose $(B),+$ phentolamine $(B),+$ propranolol $(C)$ and + combined blockade $(D)$. Circled and closed symbols as in Fig. 1.

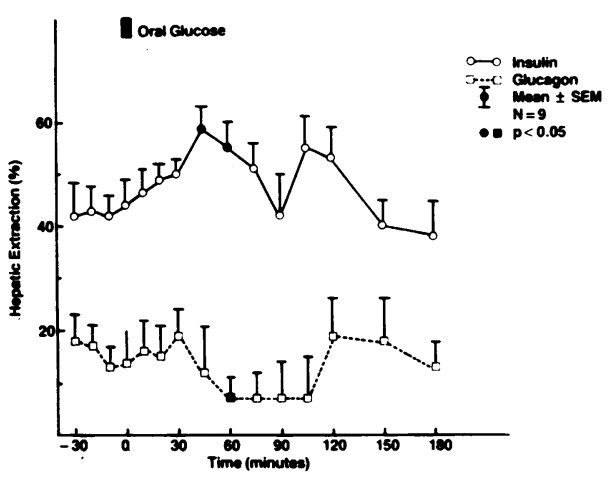

C

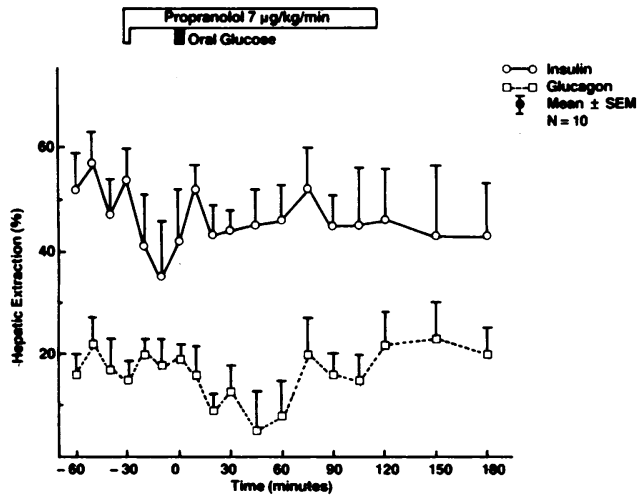

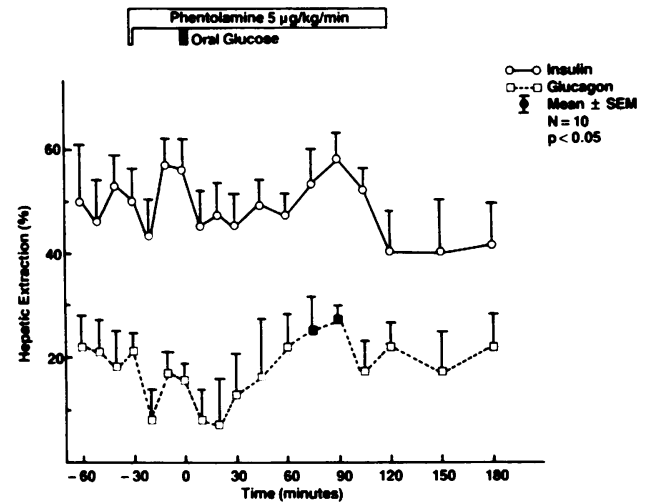

D

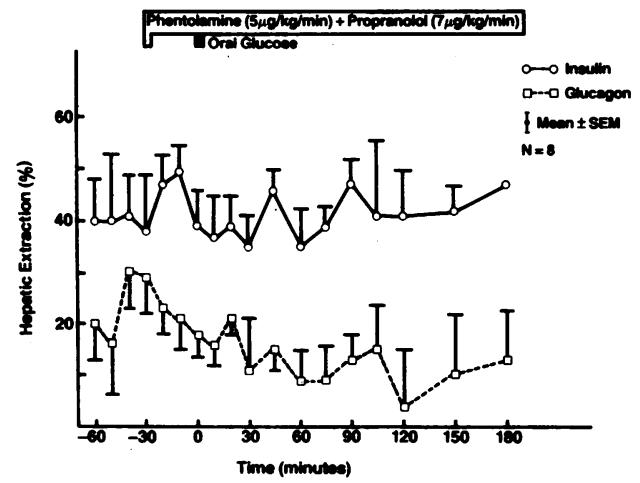

Figure 7. The fractional hepatic extraction of insulin, $\circ$; and glucagon, $\square$; before and after oral glucose administration \pm phentolamine and propranolol, separately or combined. Control oral glucose $(A),+$ phentolamine $(B)$ and + propranolol $(C)$ and + combined blockade $(D)$. Closed symbols as in Fig. 1. 
role of insulin and glucagon on basal glucose levels and glucose production observed with the adrenergic blockers is supported by the studies of Gerich et al. (13) and Best et al. (29).

The role of $\alpha$-and $\beta$-adrenergic blockade of basal adrenergic function on hepatic glucose metabolism after oral glucose has not been previously examined. After oral glucose in the control dogs, $77 \%$ of the load appeared in the portal vein during the subsequent $3 \mathrm{~h}$. Although net absorption was still occurring at this time, extrapolation of the data to the fourth hour indicated only a very small amount of additional glucose would be absorbed into the portal system. Our results are almost identical to those reported by Abumrad et al. (30) in conscious dogs using the portal-arterial difference technique as well as a radioisotopic one. The residual glucose which did not appear in the portal system was probably consumed by the extrahepatic splanchnic tissues (30). Both alpha and beta adrenergic blockade, separately and combined, significantly decreased the amount of the glucose load that appeared in the portal vein (control, 77\%; phentolamine, 54\%; propranolol, 59\%; and phentolamine + propranolol, $62 \%$ ) and also abolished the augmented portal plasma flow observed in the control dogs after oral glucose. The causal relationship between these two is not known. Our previous studies demonstrated that increased portal plasma flow after oral glucose is associated with glucose absorption and not portal hyperglycemia since similar portal hyperglycemia produced by intraportal glucose infusion did not increase portal vein flow (17). Parasympathetic innervation also seems to be important in glucose absorption and the increased portal vein flow since vagotomy (31) and infusion of atropine (32) diminished absorption of oral glucose. Atropine also abolished the increased portal vein plasma flow after oral glucose, even when the oral glucose load was doubled so that the portal vein glucose concentration was similar to that obtained with $1 \mathrm{~g} / \mathrm{kg}$ glucose in control studies. Many gut factors released during oral glucose ingestion affect portal flow (33). Since it is not known how phentolamine or propranolol affect their secretion, alterations in them could cause the reduction in net absorption and inhibition of the increase in portal plasma flow.

In the present study, the hyperinsulinemia induced by oral glucose was enhanced by $\alpha$-adrenergic and reduced by $\beta$-adrenergic blockade. The combined blockade was intermediate between that obtained with $\beta$-blockade and control but not significantly different from the latter. These differences cannot be accounted for by differences in the arterial glucose concentration since it was similar in all three experiments (control, $142 \pm 10$; phentolamine, $155 \pm 10$; propranolol, $149 \pm 7 \mathrm{mg} / 100 \mathrm{ml}$, respectively, and even greater with the combined blockade, $179 \pm 19$ $\mathrm{mg} / 100 \mathrm{ml})$. The effect of propranolol confirms the results of Cerasi et al. (15), who reported diminution of the insulin response to intravenous glucose in normal men. However, they found no effect of phentolamine. The reason for this discrepancy is not clear but is not due to the sampling site since in our experiments the difference was also manifest in the arterial plasma insulin concentrations. Suppression of glucagon was similar in the control, phentolamine, and propranolol groups, but less with the combined blockade, consistent with less net hepatic glucose uptake and greater arterial levels of glucose.

The percent of the glucose absorbed into the portal vein which was retained by the liver was similar in control $(40 \pm 6 \%)$, phentolamine $(34 \pm 6 \%)$, and propranolol $(43 \pm 6 \%)$ groups, but

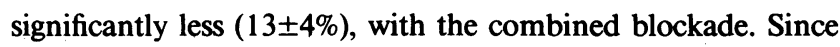
more glucose was absorbed in the absence of adrenergic blockade, the reduced amount of glucose removed by the liver, especially after combined blockade cannot be attributed to saturation of hepatic glucose uptake. The smaller net hepatic uptake of glucose with combined adrenergic blockade might reflect the higher glucagon concentrations since it and the lower insulin/glucagon molar ratio would result in less suppression of hepatic glucose production. In the control group the liver retained $31 \pm 5 \%$ of the total glucose administered, not significantly different from the values recently reported by Bergman et al. (34) and Abumrad et al. (30). These results and those measuring splanchnic glucose uptake in humans (35-37) indicate that the liver plays a smaller role than the peripheral tissues in the disposal of an oral glucose load. Our present results differ from our previous report that $68 \%$ of a similar oral glucose load was retained in the liver (17). However, this value was based on calculations in which the basal glucose output, integrated over $180 \mathrm{~min}$, was included in the total net hepatic glucose uptake. Although oral glucose suppressed basal hepatic glucose production, this amount does not really contribute to the net uptake of the exogenous glucose load. Using the same calculations that we used previously, the hepatic glucose uptake after oral glucose would be $61 \%$ in the present experiments.

In addition to the effect of hyperglycemia on net hepatic glucose uptake, the role of insulin must be considered. Cherrington et al. (38) reported that physiologic increments in plasma insulin $(33 \mu \mathrm{U} / \mathrm{ml})$ had a marked effect on hepatic glucose uptake in dogs infused with somatostatin and a basal amount of glucagon. Abumrad et al. (30) concluded that the peak insulin level after oral glucose was an important factor regulating net hepatic glucose uptake. Bergman and Buculo (39) observed that prior perfusion of the liver with insulin increased hepatic uptake of glucose by $45 \%$ and they concluded that although glucose was more important, insulin had a potentiating effect (39). Bergman (40) suggested that glucose exerted a rapid moment-to-moment influence on the rate of hepatic glucose uptake, while insulin was very effective in optimizing the amount of glycogen stored in the liver during carbohydrate ingestion. Since our results indicate that hyperglycemia, hyperinsulinemia, and hypoglucagonemia, as will be discussed subsequently, are all important factors contributing to the suppression of hepatic glucose production, it is not surprising that Cherrington et al. (38) did not observe net hepatic uptake in their experiments without insulin (38). Although their animals had hyperglycemia, they had hypoinsulinemia and basal levels of glucagon that would favor hepatic glucose production. In contrast, our results do not support a direct effect of insulin in regulating net hepatic glucose uptake beyond its suppressive effect on glucose production as will be discussed subsequently. Thus, the fractional hepatic uptake of glucose was the same in the control, propranolol, and phentolamine groups despite markedly different amounts of insulin presented to the liver. The amount of insulin presented to the liver was similar in the control and combined $\alpha$ - and $\beta$ adrenergic blocked animals, but the fractional hepatic uptake of glucose was significantly less in the latter group. It is possible that even though the amounts of insulin presented to the liver are quite different, they all exceeded the threshold amount that is necessary to facilitate the effect of glucose on net hepatic glucose uptake. It was reported that peripheral insulin concentra- 
tions as low as $60 \mu \mathrm{U} / \mathrm{ml}$ after peripheral administration of the hormone were saturating for suppression of hepatic glucose production under euglycemic clamp conditions (41). However, if this is the case, our data indicate that the physiologic hyperinsulinemia after oral glucose is well above that required to exert a maximal effect on hepatic glucose uptake and that the correlation from moment to moment between insulin levels and net hepatic glucose uptake is in fact secondary to two direct correlations: $(a)$ the correlation between hyperglycemia and hyperinsulinemia; $(b)$ the correlation between amounts of glucose presented to the liver and net hepatic glucose uptake.

The present results provide further evidence that the hepatic uptake of glucose is not directly related to the hepatic extraction of insulin (17). Thus, the fractional hepatic uptake of glucose was similar after oral glucose despite the presence or absence of $\alpha$ and $\beta$ adrenergic blockade, but the fractional hepatic uptake of insulin was significantly greater after oral glucose without such blockade. In addition, fractional hepatic extraction of insulin was similar after separate and combined $\alpha$ - and $\beta$-blockade, but the fractional hepatic uptake of glucose was significantly less after the latter. Furthermore, hepatic glucose uptake was similar after oral and intraportal glucose administration, but only the former was associated with augmented fractional hepatic extraction of insulin (17). In contrast, Jaspan and Polonsky (42) suggested that the increased fractional hepatic extraction of insulin was an important factor in regulating hepatic glucose uptake. However, this suggestion was based simply on the fact that such augmented hepatic extraction occurred after oral glucose. The present results suggest that the increased portal vein flow after oral glucose might be an important factor in the greater fractional hepatic extraction of insulin since both were abolished by separate and combined $\alpha$ and $\beta$ adrenergic blockade. In addition, atropine infusion blocked both the increased portal plasma flow and fractional hepatic extraction of insulin after oral glucose (32). Furthermore, ingestion of meat was also associated with both increased portal plasma flow and fractional hepatic extraction of insulin (43). However, this relationship does not always exist since infusion of arginine and cholecystokinin-pancreozymin augmented portal plasma flow but fractional hepatic extraction of insulin decreased (44).

The effect of insulin to suppress (1, 2, 25-27) and glucagon to stimulate $(1,2,25-27)$ net hepatic glucose production was confirmed in the present experiments. These effects of insulin and glucagon may have an influence on the measurement of net hepatic glucose uptake. In our experiments net endogenous glucose production was usually suppressed to zero by $10 \mathrm{~min}$ after the oral administration of glucose except in the combined blockade group, in which glucagon decreased less. In a small number of dogs, such suppression occurred later, which contributed to a small residual glucose output from endogenous sources. However, in the vast majority of the dogs, the residual output of glucose during the 180 -min period reflected resumption of hepatic glucose production after the return of the hyperglycemia to normal. Thus, studies using splanchnic balance (hepatic vein catheterization only) for the estimation of net splanchnic glucose balance may include a considerable amount of endogenous glucose in addition to the exogenous glucose that escaped hepatic retention. This would be especially important when the results are calculated over a 4-h period $(35,36,45)$. In the present experiments hepatic glucose production resumed despite the fact that glucose absorption had not ceased at $180 \mathrm{~min}$. This is consistent with previous results in humans using a radioisotopic technique (46). The resumption of hepatic glucose production occurred earlier with $\alpha$ adrenergic blockade. This could reflect the significantly greater hyperinsulinemia which would accelerate peripheral glucose utilization and reestablish normal plasma glucose levels earlier. Our results support such augmented peripheral glucose clearance after phentolamine rather than a change in hepatic uptake of glucose as the explanation for the more rapid reestablishment of normoglycemia. Such increased peripheral utilization of glucose could activate counterregulatory mechanisms, which would prevent hypoglycemia late after oral glucose $(5,10)$. The important role of glucagon in such counterregulation is suggested since its concentration began to rise earlier after the initial suppression by glucose in the experiments in which phentolamine was infused. The predominant role for glucagon in counterregulation has been recently demonstrated (10). The fact that the hyperinsulinemia after oral glucose with or without $\alpha$ or $\beta$ adrenergic blockade did not correlate with net hepatic glucose uptake but did with the total disposal of glucose, indicates a significant difference between the role of insulin in the regulation of hepatic and peripheral glucose uptakes.

The involvement of other glucoregulatory hormones during hyperglycemia after oral glucose is possible but less likely. Recently, Tse et al. (5) reported that among the potentially important glucose regulatory factors, only a transient increment in insulin, a transient decrement in glucagon, and a late increment in epinephrine (well after the return of hyperglycemia to basal) were specific for glucose ingestion. Growth hormone, cortisol, and norepinephrine were not. Although norepinephrine does increase after oral glucose (5), it also increases after xylose, mannitol, and water ingestions without any change in glucose levels. In addition, it has been shown that hyperglycemia, per se, can offset stimulated adrenergic effects on glucose production $(7,47,48)$. Finally, in the present study the net effect of phentolamine was to suppress and that of propranolol to increase basal hepatic glucose production. It is unlikely that during hyperglycemia those effects were reversed. As for the involvement of central innervation, selective denervation of the liver had no effect on glucose metabolism (49).

The present studies demonstrate that the action of $\alpha$ - and $\beta$-adrenergic blockade on basal hepatic glucose output reflects their direct effect on insulin and glucagon secretion. Both $\alpha-$ and $\beta$-adrenergic blockade decrease net glucose absorption and the associated increase in portal vein plasma flow. While combined blockade canceled the opposite effects of phentolamine and propranolol on basal insulin as well as the response after oral glucose, this was not the case regarding glucagon responses, net glucose absorption into the portal system, or the effects on portal plasma flow. In addition the opposite effects of $\alpha$ - and $\beta$ adrenergic blockade on net hepatic glucose output were not neutralized by combined adrenergic blockade. The lack of such neutralization of the opposite effects of $\alpha$ - and $\beta$-adrenergic blockade by combined phentolamine and propranolol might indicate an unequal magnitude of such effects of the $\alpha$ - or the $\beta$ adrenergic action. Furthermore, the net hepatic glucose uptake may be more related to the amounts of glucose but not the amounts of insulin reaching the liver or its absolute or fractional hepatic extraction. Finally, the alterations in oral glucose tolerance after $\alpha$ - and $\beta$-blockade represent changes in peripheral 
glucose utilization due to changes in peripheral insulin concentrations rather than hepatic glucose uptake. The effect of glucagon on net hepatic glucose production may also play a role.

\section{Acknowledgments}

The authors are indebted to the staff of Cardiovascular Sciences for their superb help in the execution of these experiments, and to Mr. Jesse Chou for his expert execution of the hormone assays. We would also like to thank Jamie Hubbard, Mary Ann Farabee, and Shelley Dearing for their outstanding assistance in the preparation of this manuscript.

This work was supported by U. S. Public Health Service grants AM 25253 and the Diabetes and Endocrinology Research Center AM 27685 from National Institutes of Health.

\section{References}

1. Altszuler, N., B. Gottlieb, and J. Hampshire. 1976. Interaction of somatostatin, glucagon and insulin on hepatic glucose output in the normal dog. Diabetes. 25:116-121.

2. Cherrington, A. D., J. L. Chiasson, J. E. Liljenquist, A. S. Jennings, U. Keller, and W. W. Lacey. 1976. The role of insulin and glucagon in the regulation of basal glucose production in the postabsorptive dog. $J$. Clin. Invest. 58:1407-1418.

3. Clarke, W. L., J. V. Santiago, L. Thomas, E. Ben-Galim, M. W. Haymond, and P. E. Cryer. 1979. The role of adrenergic mechanisms in recovery from hypoglycemia in man: Studies with adrenergic blockade. Am. J. Physiol. 236:E147-E152.

4. Walter, R. M., R. J. Dudl, J. P. Palmer, and J. W. Ensinck. 1974. The effect of adrenergic blockade on the glucagon responses to starvation and hypoglycemia in man. J. Clin. Invest. 54:1214-1220.

5. Tse, T. F., W. E. Clutter, S. D. Shah, J. P. Miller, and P. E. Cryer. 1983. Neuroendocrine responses to glucose ingestion in man. Specificity, temporal relationships and quantitative aspects. J. Clin. Invest. 72:270277.

6. Sacca, L., N. Eigler, P. E. Cryer, and R. S. Sherwin. 1979. Insulin antagonistic effects of epinephrine and glucagon in the dog. Am. J. Physiol. 237:E487-E492.

7. Sacca, L., C. Vigorito, M. Cicala, B. Ungaro, and R. S. Sherwin. 1982. Mechanisms of epinephrine-induced glucose intolerance in normal humans. Role of the splanchnic bed. J. Clin. Invest. 69:284-293.

8. Rizza, R. A., P. E. Cryer, M. W. Haymond, and J. E. Gerich. 1980. Adrenergic mechanisms for the effects of epinephrine on glucose production and clearance in man. J. Clin. Invest. 65:682-689.

9. Rizza, R. A., P. E. Cryer, and J. E. Gerich. 1979. Role of glucagon, catecholamines and growth hormone in human glucose counterregulation: Effects of somatostatin and combined $\alpha$ - and $\beta$-adrenergic blockade on plasma glucose recovery and glucose flux rates after insulin-induced hypoglycemia. J. Clin. Invest. 64:62-71.

10. Tse, T. F., W. E. Clutter, S. D. Shah, and P. E. Cryer. 1983. Mechanisms of postprandial glucose counterregulation in man. Physiologic roles of glucagon and epinephrine vis-a-vis insulin in the prevention of hypoglycemia late after glucose ingestion. J. Clin. Invest. 72:278-286.

11. Porte, D., Jr. 1967. A receptor mechanism for the inhibition of insulin release by epinephrine in man. J. Clin. Invest. 46:86-94.

12. Robertson, R. P., and D. Porte, Jr. 1973. Adrenergic modulation of basal insulin secretion in man. Diabetes. 22:1-8.

13. Gerich, J. E., M. Langlois, C. Noacco, V. Schneider, and P. H. Forshman. 1974. Adrenergic modulation of pancreatic glucagon secretion in man. J. Clin. Invest. 53:1441-1446.

14. Koerker, D. J., and J. B. Halter. 1982. Glucoregulation during insulin and glucagon deficiency: role of catecholamines. Am. J. Physiol. 243:E225-E233.

15. Cerasi, E., R. Luft, and S. Efendic. 1972. Effect of adrenergic blocking agents on insulin response to glucose infusion in man. Acta. Endocrinol. 69:335-346.
16. Ishida, T., K. M. Lewis, C. J. Hartley, M. Entman, and J. B. Field. 1983. Comparison of hepatic extraction of insulin and glucagon in conscious and anesthetized dogs. Endocrinology. 112:1098-1109.

17. Ishida, T., Z. Chap, J. Chou, R. Lewis, C. Hartley, M. Entman, and J. B. Field. 1983. Differential effects of oral, peripheral intravenous and intraportal glucose on hepatic glucose uptake and insulin and glucagon extraction in conscious dogs. J. Clin. Invest. 72:590-601.

18. Hartley, C. J., and J. S. Cole. 1974. An ultrasonic pulsed Doppler system for measuring blood flows in small vessels. J. Appl. Physiol. 37: 626-629.

19. Hartley, C. J., H. G. Hanley, R. M. Lewis, and J. S. Cole. 1978. Synchronized pulsed Doppler blood flow and ultrasonic dimension measurement in conscious dogs. Ultrasound Med. Biol. 4:99-110.

20. Herbert, V., K. S. Lau, C. W. Gottlieb, and S. J. Bleicher. 1965. Coated charcoal immunoassay of insulin. J. Clin. Endocrinol. Metab. 25:1375-1379.

21. Faloona, G. R., and R. H. Unger. 1974. Glucagon in methods of hormone radioimmunoassay. B. M. Jaffee and H. R. Berman, editors. Academic Press, Inc., New York. 317-330.

22. Brockman, R. P., and R. Halvorson. 1982. Glucose, glucagon and insulin during adrenergic blockade in exercising sheep. J. Appl. Physiol. 52:315-319.

23. Altszuler, N., E. Moraru, B. Gottlieb, and J. Hampshire. 1978. Effect of isoproterenol on glucose turnover and insulin secretion in the normal dog. Biochem. Pharmacol. 27:769-772.

24. William-Olsson, T., E. Fellenius, F. P. Bjorntorp, and U. Smith. 1979. Differences in metabolic responses to $\beta$-adrenergic stimulation after propranolol or metoprolol administration. Acta. Med. Scand. 205: 201-206.

25. Madison, L. L., B. Combes, R. Adams, and W. Strickland. 1960. The physiological significance of the secretion of endogenous insulin into the portal circulation. III. Evidence for a direct immediate effect of insulin on the balance of glucose across the liver. J. Clin. Invest. 39:507522.

26. Parrilla, R., M. N. Goodman, and C. J. Towes. 1974. Effect of glucagon:insulin ratios on hepatic metabolism. Diabetes. 23:725-731.

27. Felig, P., R. Gusberg, R. Hendler, F. E. Gump, and J. M. Kinney. 1974. Concentration of glucagon and the insulin:glucagon ratio in the portal and peripheral circulation. Proc. Soc. Exp. Biol. Med. 147:88-90.

28. Baxter, J., and J. Funder. 1979. Hormone receptors. N. Engl. J. Med. 301:1149-1162.

29. Best, J. D., W. K. Ward, M. A. Pfeifer, and J. B. Halter. 1984. Lack of a direct $\alpha$-adrenergic effect of epinephrine on glucose production in human subjects. Am. J. Physiol. 246:E271-E276.

30. Abumrad, N. N., A. D. Cherrington, P. E. Williams, W. W. Lacy, and D. Rabin. 1982. Absorption and disposition of a glucose load in the conscious dogs. Am. J. Physiol. 242:E398-E406.

31. Radziuk, J., and D. C. Bondy. 1982. Abnormal oral glucose tolerance and glucose malabsorption after vagotomy and pyloroplasty: a tracer method for measuring glucose absorption rates. Gastroenterology. 83:1017-1025.

32. Chap, Z., T. Ishida, J. Chou, R. Lewis, C. J. Hartley, M. L. Entman, and J. B. Field. 1985. Effects of atropine and gastric inhibitory polypeptide on hepatic glucose uptake and insulin extraction in conscious dogs. J. Clin. Invest. 76:1174-1181.

33. Chou, C. C., M. J. Mangino, and D. R. Sawmiller. 1984. Gastrointestinal hormones and intestinal blood flow. In Physiology of Intestinal Circulation. A. P. Shepherd and D. N. Granger, editors. Raven Press, New York. 121-130.

34. Bergman, R. N., J. R. Bier, and P. M. Hourigan. 1982. Intraportal glucose infusion matched to oral glucose absorption. Lack of evidence for "Gut Factor" involvement in hepatic glucose storage. Diabetes. 31: 27-35.

35. Katz, L. D., M. G. Glickman, S. Rapoport, E. Ferrannini, and R. A. De Fronzo. 1983. Splanchnic and peripheral disposal of oral glucose in man. Diabetes. 32:675-679. 
36. De Fronzo, R. A., L. D. Katz, G. Rechard, J. Wahren, and E. Ferrannini. 1983. Disposal of oral glucose in man. Diabetes. 32(Suppl. 1):52a (Abstr.)

37. Wahren, J., O. Bjorkman, L. S. Eriksson, and P. Felig. 1983. The second meal phenomenon: rapid induction of peripheral insulin resistance by prior ingestion of glucose. Diabetes. 32(Suppl. 1):53a (Abstr.)

38. Cherrington, A. D., P. E. Williams, N. Abou-Mourad, W. W. Lacy, K. E. Steiner, and J. E. Liljenquist. 1982. Insulin as a mediator of hepatic glucose uptake in the conscious dog. Am. J. Physiol. 242:E97E101.

39. Bergman, R. N., and R. J. Bucolo. 1974. Interaction of insulin and glucose in the control of hepatic glucose balance. Am. J. Physiol. 227:E1314-E1322.

40. Bergman, R. N. 1977. Integrated control of hepatic glucose metabolism. Fed. Proc. 36:265-270.

41. Rizza, R. A., L. J. Mandarino, and J. E. Gerich. 1981. Doseresponse characteristics for the effects of insulin on production and utilization of glucose in man. Am. J. Physiol. 240:E630-E639.

42. Jaspan, J., and K. Polonsky. 1982. Glucose ingestion in dogs alters the hepatic extraction of insulin. In vivo evidence for a relationship between biologic action and extraction of insulin. J. Clin. Invest. 69: 516-525.
43. Ishida, T., J. Chou, R. M. Lewis, C. J. Hartley, M. Entman, and J. B. Field. 1983. The effect of ingestion of meat on hepatic extraction of insulin and glucagon and hepatic glucose output in conscious dogs. Metabolism. 32:558-567.

44. Ishida, T., R. M. Lewis, C. J. Hartley, M. L. Entman, and J. B Field. 1983. Comparison of hepatic extraction of insulin and glucagon in conscious and anesthetized dogs. Endocrinology. 112:1098-1119.

45. Felig, P., J. Wahren, and R. Handler. 1975. Influence of oral glucose ingestion on splanchnic glucose and gluconeogenic substrate metabolism in man. Diabetes. 24:468-475.

46. Radziuk, J., T. J. McDonald, D. Rubenstein, and J. Dupre. 1978. Initial splanchnic extraction of ingested glucose in normal man. Metabolism. 27:657-669.

47. Shulman, G. I., J. E. Liljenquist, P. E. Williams, W. W. Lacy, and A. D. Cherrington. 1978. Glucose disposal during insulinopenia in somatostatin-treated dogs. The roles of glucose and glucagon. J. Clin. Invest. 62:487-491.

48. Sacca, L., R. Hendler, and R. S. Sherwin. 1978. Hyperglycemia inhibits glucose production in man independent of changes in glucoregulatory hormones. J. Clin. Endocrinol. Metab. 47:1160-1163.

49. Mikenes, K. J., B. Sonne, E. A. Richter, N. J. Christensen, and H. Galbo. 1985. Glucose turnover during insulin-induced hypoglycemia in liver-denervated rats. Am. J. Physiol. 248:E327-E332. 